\title{
Evaluation of Job Satisfaction of Class III and Class IV Workers in a Tertiary Medical Care Centre, Maharashtra
}

\author{
Shravani Deolia ${ }^{1}$, Shreya Choudhary ${ }^{2}$, Savi Vora ${ }^{3}$, Amit Reche ${ }^{4}$, Kumar Gaurav Chhabra ${ }^{5}$, Sourav Sen ${ }^{6}$
}

\begin{abstract}
1Department of Public Health Dentistry, Sharad Pawar Dental College, Datta Meghe Institute of Medical Sciences (Deemed to be University), Sawangi (Meghe), Wardha, Maharashtra, India. ${ }^{2}$ Department of Public Health Dentistry, Sharad Pawar Dental College, Datta Meghe Institute of Medical Sciences (Deemed to be University), Sawangi (Meghe), Wardha, Maharashtra, India. ${ }^{3}$ Department of Public Health Dentistry, Sharad Pawar Dental College, Datta Meghe Institute of Medical Sciences (Deemed to be University), Sawangi (Meghe), Wardha, Maharashtra, India. ${ }^{4}$ Department of Public Health Dentistry, Sharad Pawar Dental College, Datta Meghe Institute of Medical Sciences (Deemed to be University), Sawangi (Meghe), Wardha, Maharashtra, India. ${ }^{5}$ Department of Public Health Dentistry, M. M College of Dental Sciences and Research (Mullana), Ambala, Haryana, India. ${ }^{6}$ Department of Public Health Dentistry, M. M College of Dental Sciences and Research (Mullana), Ambala, Haryana, India.
\end{abstract}

\section{ABSTRACT}

\section{BACKGROUND}

Job satisfaction level helps to identify an individual's general attitude and interest towards workplace. The aim of the present study was to evaluate the level of job satisfaction of Class III and Class IV workers in healthcare institution in Maharashtra.

\section{METHODS}

The study was conducted among 100 employees of which, 52 were Class III and 48 were Class IV workers. A questionnaire containing 17 items was used (UWES-17). UWES is a test to measure work engagement both on an individual and on group level. UWES utilizes three scales to determine the level of work engagement: vigour, dedication, and absorption. All these items were in 7-point Likert scale with a score range from zero (never) to six (always). Higher scores in all cases indicated greater job satisfaction. Data was analysed using independent t-test and one-way ANOVA.

\section{RESULTS}

The result showed that satisfaction value is slightly more in Class IV workers (35.04) with a statistically significant (0.011) value.

\section{CONCLUSIONS}

Findings of this study show that modification in the workplace will aid in increasing the involvement of employees that will further increase productivity level in organizations and job satisfaction among workers.

\section{KEY WORDS}

Absorption, Dedication, Job Satisfaction, UWES-17, Vigour, Work-Engagement.
Corresponding Author: Dr. Shravani Deolia, Department of Public Health Dentistry, Sharad Pawar Dental College, Datta Meghe Institute of Medical Sciences, (Deemed to be University), Sawangi-442001 (Meghe), Wardha, Maharashtra, India.

E-mail: deoliashravani@gmail.com

DOI: $10.14260 / j e m d s / 2019 / 832$

Financial or Other Competing Interests: None.

How to Cite This Article:

Deolia S, Choudhary S, Vora $S$, et al. Evaluation of job satisfaction of class iii and class iv workers in a tertiary medical care centre, Maharashtra. J. Evolution Med. Dent. Sci. 2019;8(51):3841-3845, DOI: 10.14260/jemds/2019/832

Submission 25-09-2019, Peer Review 03-12-2019, Acceptance 10-12-2019, Published 23-12-2019. 


\section{BACKGROUND}

The need and demand for health care has exceeded the capacity of the well-maintained professions in order to provide complete, comprehensive and appropriate services, while taking into account the prevention of disease. Thus, leading to special attention in medicine, dentistry and nursing sciences, as in any other health service. [1] Working in the medical profession is acknowledged both physically and mentally demanding profession. 'A satisfied worker is a happy worker', this statement by Robbins.[2] Sums up the importance of job satisfaction level among people. Locke had stated that job satisfaction is the positive emotional state resulting from the appraisal of one's job and job experiences. ${ }^{[3]}$

Every organization tries to achieve their objectives by making the best use of people as a valuable resource of the organization and attention must be given to the relationship between staff and the nature and content of their jobs. The organization and the design of jobs can have a significant effect on staff. Attention needs to be given to the quality of working life. Mental health at workplace was the theme stated by World Mental Health Day in 2017. Worldwide, more than 300 million people are suffering from depression and more than 260 million had been experiencing anxiety disorders while many of them live with both. A recent WHOled study estimated that a sum amount of US\$ 1 trillion is lost for the treatment of depression and anxiety disorders globally.[4] Hence, sixty-sixth World Health Assembly had adopted an Action Plan of WHO's Comprehensive Mental Health in 2013-2020 May 2013. [5,6] WHO stated that stress at the workplace is inevitable due to the demands of the present work scenario. Pressure when perceived as acceptable by an individual, may keep workers attentive, inspired, able to work and learn but when that pressure becomes imprudent or otherwise unmanageable it summons up to stress. Stress can vandalize the workers' health and work efficiency. Stress results from an imbalance between the demands and pressures on the person, on the one hand, and their knowledge, dedication and abilities on the other. [7]

In general, job satisfaction level helps to identify an individual's general attitude and interest towards his or her job. Clearly, a person with a high level of job satisfaction invariably holds positive attitude and enthusiasm towards his job, while a dissatisfied person holds negative attitude about the job.[2] Job satisfaction has been associated to various aspects of patient care and health system outcomes in medical field[8] as well as to general life satisfaction. ${ }^{[9]}$ Job satisfaction is therefore not a single entity but a complex set of interrelationship of tasks, roles, dedication, behaviour, responsibilities, interactions, incentives and rewards.[10] The concept of job satisfaction defined by Herzberg and Mausner states the difference between intrinsic satisfaction such as recognition, the work tasks themselves and the level of or responsibility on the one hand, and extrinsic factors like working conditions, management indulgence, company policy or salary, which influence job satisfaction on the other hand.[11]

Poor satisfaction is linked with suboptimal healthcare delivery system and poor clinical outcomes, maybe due to adverse events and reduced patient adherence.[12] Job dissatisfaction is a major cause of nurses' turnover and a shortage of nonphysician personnel. Another negative consequence of high turnover is a loss of continuity of care. For the healthcare workers themselves, a reduced job satisfaction is also related with increased levels of stress and burnout. Furthermore, it may affect patient satisfaction with care. It is known that working conditions have a significant impact on job satisfaction and a high workload is related with a lower work performance at primary care practices.

Although other sources may state different figures, it is clear that occupationally induced stress is a major problem for both individual employees and organizations. Recently some organizations have begun to respond to the problems of occupational stress by promoting employee health through stress reduction programs plan and implementing them. Job satisfaction may be an important predictor within the medical profession and the intention to change the job.[13] Many studies in abroad have been carried out to explore this topic. [14-18]

Job satisfaction can be directly related to work engagement. Work engagement is truly related to job characteristics that might be tagged as resources, motivators or inspirations, such as interactions with colleagues and one's seniors, performance feedback, coaching, job autonomy, variety of tasks, and training facilities. Moreover, work engagement is positively related with productivity and satisfaction of the worker that may precede engagement. [19] There are various studies performed at different professional level in the institute, yet less importance has been given to Class III and Class IV workers. In the university setup, no similar study conducted regarding job satisfaction on Class III and Class IV workers and hence, this study is about job motivation and satisfaction in Maharashtra. This study aims to evaluate the job satisfaction of Class III and Class IV workers in healthcare institution in Maharashtra.

\section{METHODS}

This cross-sectional study was conducted on Class III and Class IV workers at private healthcare institute in Maharashtra during the period of February-May in 2018. Before starting the study, approval was obtained from ethical committee. Employees who have been working in the college for more than a year were included in the study and who have been working for less than a year and those who were not willing to cooperate were excluded from the study. They were informed that responses would be confidential and preserved.

The questionnaire collected the information relating to characteristics of employees, like qualification, area of practice and job satisfaction and was assessed by a 17-item job satisfaction questionnaire developed by Utrecht Work Engagement Scale (UWES). All the variables were scored on a 7-point Likert scale and the value was ranging from 0 to 6 . UWES is a test of how to measure work engagement both on an individual and on group level. The UWES utilizes three scales to determine the level of work engagement: vigour, dedication, and absorption. [20]

The first component that is Vigour can be assessed by the six items that refers to the high level of energy and resilience, the willingness to invest effort, not being easily fatigued and persistence in the time of difficulties. Dedication is assessed 
by five items that refers to deriving a sense of significance from one's work, feeling enthusiastic and proud about one's job, and feeling inspired and challenged by it. The third and last component, Absorption, is assessed by six items that refers to be happily immersed in one's work and having all the workplace difficulties detach from oneself so that time passes quickly, and one forgets everything else that is occurring around. [20]

\section{Statistical Analysis}

The analyses were performed using SPSS (11.5 version). The differences between Class III and Class IV workers were analysed using independent t-test and one-way ANOVA. In addition to it, a descriptive analysis in relation with the overall job satisfaction was performed and seventeen items of the job satisfaction scale were used for Class III and Class IV workers. Post-hoc was done. A significant value $(\mathrm{p}<0.05)$ was used for tests of statistical significance.

\section{RESULTS}

\begin{tabular}{|c|c|c|}
\hline \multirow{2}{*}{ Gender } & Male & 61 \\
\cline { 2 - 3 } & Female & 39 \\
\hline \multirow{2}{*}{ Designation } & Class III & 52 \\
\cline { 2 - 3 } & Class IV & 48 \\
\hline \multirow{2}{*}{ Work tenure } & $<5$ years & 40 \\
\cline { 2 - 3 } & $>5$ years & 60 \\
\hline \multirow{2}{*}{ Age } & $18-30$ years & 26 \\
\cline { 2 - 3 } & $31-45$ years & 46 \\
\cline { 2 - 3 } & $46-60$ years & 28 \\
\hline \multicolumn{2}{|c|}{$\mathbf{1 0 0}$} \\
\hline \multicolumn{2}{|c|}{ Total } & \multicolumn{2}{|c|}{} \\
\hline \multicolumn{2}{|c|}{ Table 1. Demographic Details of Study Participants } \\
\hline
\end{tabular}

\begin{tabular}{|c|c|c|c|}
\hline & Male & Female & p Value \\
\hline Vigour & $34.48 \pm 3.12$ & $34.67 \pm 2.97$ & 0.703 \\
\hline Dedication & $28.56 \pm 2.59$ & $28.90 \pm 1.80$ & 0.120 \\
\hline Absorption & $33.26 \pm 4.11$ & $33.95 \pm 3.47$ & 0.112 \\
\hline \multicolumn{4}{|c|}{ Table 2. Comparison of Mean Scores among Gender Using } \\
Unpaired 't' Test \\
\hline
\end{tabular}

\begin{tabular}{|c|c|c|c|}
\hline & Class III & Class IV & p Value \\
\hline Vigour & $34.10 \pm 3.32$ & $35.04 \pm 2.67$ & $0.011^{*}$ \\
\hline Dedication & $28.52 \pm 2.25$ & $28.88 \pm 2.38$ & 0.531 \\
\hline Absorption & $33.56 \pm 3.75$ & $33.50 \pm 4.03$ & 0.517 \\
\hline \multicolumn{4}{|c|}{ Table 3. Comparison of Mean Scores Based on their Designation } \\
Using Unpaired 't' Test \\
\hline${ }^{*} \mathrm{p}<0.05$; significant
\end{tabular}

\begin{tabular}{|c|c|c|c|}
\hline Work Tenure & Less than 5 Years & More than 5 Years & p Value \\
\hline Vigour & $34.75 \pm 2.99$ & $34.42 \pm 3.10$ & 0.448 \\
\hline Dedication & $28.63 \pm 2.31$ & $28.73 \pm 2.34$ & 0.881 \\
\hline Absorption & $33.18 \pm 4.11$ & $33.77 \pm 3.71$ & 0.505 \\
\hline \multicolumn{3}{|c|}{ Table 4. Comparison of Mean Scores Based on their Work Tenure } \\
Using Unpaired 't' Test \\
\hline
\end{tabular}

According to data collected, out of 100 workers, 61 were males while 39 were females and among them 52 were Class III workers and 48 were Class IV workers. Among them, 60 of the workers are working in the institute for more than five years and 40 workers are working for less than five years. Majority of them belongs to age group of 31-45 years (46), some of them are in 46-60 years (28) and rests of them are in age group of 18-30 years (26).

Table 02 compares the vigour between female workers $(34.67 \pm 2.97)$ and male workers $(34.48 \pm 3.12)$ and this was statistically not significant (0.703). Comparison of dedication and absorption was also statistically not significant $(0.120$;
0.112 respectively). Table 03 shows that for vigour, the value is slightly more in Class IV workers (35.04 \pm 2.67$)$ when compared to Class III workers $(34.10 \pm 3.32)$ and this was statistically significant (0.011).

From table 04, it was observed that the value of dedication and absorption to a small degree is more in workers who are working for more than five years $(28.73 \pm 2.34 ; 33.77 \pm 3.71$ respectively) than workers who have worked less than five years $(28.63 \pm 2.31 ; 33.18 \pm 4.11$ respectively) but was statistically not significant $(0.881$; 0.505 respectively).

\begin{tabular}{|c|c|c|c|c|c|}
\hline & Between Colleges & \begin{tabular}{|l|l} 
Mean & I \\
\end{tabular} & F value & Signific & cance Value \\
\hline \multirow{3}{*}{ Vigour } & Dental & 34.12 & \multirow{3}{*}{0.97} & \multirow{3}{*}{\multicolumn{2}{|c|}{0.373}} \\
\hline & Medical & 34.98 & & & \\
\hline & Nursing & 35.00 & & & \\
\hline \multirow{3}{*}{ Dedication } & Dental & 28.40 & \multirow{3}{*}{0.84} & \multirow{3}{*}{\multicolumn{2}{|c|}{0.435}} \\
\hline & Medical & 28.93 & & & \\
\hline & Nursing & 29.20 & & & \\
\hline \multirow{3}{*}{ Absorption } & Dental & 33.32 & \multirow{3}{*}{0.81} & \multirow{3}{*}{\multicolumn{2}{|c|}{0.449}} \\
\hline & Medical & 33.43 & & & \\
\hline & Nursing & 35.00 & & & \\
\hline \multicolumn{6}{|c|}{ Post HOC } \\
\hline $\begin{array}{c}\text { Dependent } \\
\text { Variable }\end{array}$ & \multicolumn{2}{|c|}{ Between Colleges } & \multicolumn{2}{|c|}{ Mean Difference } & Significance \\
\hline \multirow{3}{*}{ Vigour } & Dental & Medical & \multicolumn{2}{|c|}{0.86} & 0.19 \\
\hline & Dental & Nursing & \multicolumn{2}{|c|}{0.88} & 0.41 \\
\hline & Medical & Nursing & \multicolumn{2}{|c|}{0.86} & 0.19 \\
\hline \multirow{3}{*}{ Dedication } & Dental & Medical & \multicolumn{2}{|c|}{0.03} & 0.98 \\
\hline & Dental & Nursing & \multicolumn{2}{|c|}{0.53} & 0.41 \\
\hline & Medical & Nursing & \multicolumn{2}{|c|}{0.80} & 0.32 \\
\hline \multirow{3}{*}{ Absorption } & Dental & Medical & \multirow{2}{*}{\multicolumn{2}{|c|}{$\begin{array}{l}0.53 \\
0.28\end{array}$}} & 0.79 \\
\hline & Dental & Nursing & & & 0.46 \\
\hline & Medical & Nursing & \multicolumn{2}{|c|}{0.37} & 0.35 \\
\hline
\end{tabular}

Table 5. Comparison of Colleges Using One-Way ANOVA and Post-HOC

Table 05 compares the overall difference within colleges and between colleges that shows no significant difference between them. According to vigour, the mean value for dental, medical and nursing college comes out to be 34.12 , 34.98 and 35.00 respectively but with no significant value (0.373). Furthermore, when the comparison was done between the colleges, the mean difference between dental and medical college came out to be 0.86 that was also found to be statistically not significant $(0.19)$.

As per dedication, it was observed that the mean value for dental, medical and nursing college comes out to be 28.40 , 28.93 and 29.20 respectively but with no significant value (0.435). In addition, when the comparison was made between the colleges, no significant value was observed $(0.32 ; 0.41$ respectively) between medical-nursing and dental-nursing. The mean value of absorption from the above table for dental, medical and nursing college comes out to be $33.32,33.43$ and 35.00 respectively but with no significant value $(0.449)$. The above table also compares the value of dedication between dental and medical and between medical and nursing which also comes out to be statistically not significant $(0.79 ; 0.35$ respectively).

\section{DISCUSSION}

This is the first study on Class III and Class IV workers inquiring about job satisfaction in Wardha, Maharashtra. High positive impact on job satisfaction had the reduction of working hours, satisfaction with income, professional evaluation and appreciation, possibility to realized one's capabilities and talent to improve and quality them. All these 
factors together show that the most important things for workers to be satisfied with their job is to have possibility to develop professional upliftment. It is also known that personal time, professional relations, work organization and workload are the important factors that greatly affect job satisfaction.

The work engagement as measured in this study with the UWES-17 scale indicated that female employees felt slightly more engaged (34.67) than male employees (34.48) and this was contrary to the study led by Schaufeli and Bakker [20] in which men scored slightly higher on engagement than women but again the differences in both the studies hardly bear any practical significance. Another study by Randy Hudson showed that women are more satisfied with their work.[21] The reason for this might include family responsibilities and personal expectations that are one of the major determinants of job satisfaction.

As far as the professional level of groups are concerned, the value of vigour is slightly more in Class IV workers $(35.04 \pm 2.67)$ when compared to Class III workers $(34.10 \pm 3.32)$ which is similar to the study conducted by Ann Adams [22] showed that staff nurses are slightly more satisfied that head nurses. However, results were contrary to study by Schaufeli and Bakker where higher group of professionals were relatively more satisfied. [20] This may be due to requirement of certain level of work engagement.

The length of service is related to employees' level of job satisfaction. The present study showed that workers whose work tenure is more than 5 years were more satisfied and this was found similar to the study conducted by Titus Oshagbemi which indicated that higher the length of service; higher the job satisfaction.[23] But in both studies, practical significance was not found. Hence, it can be concluded that the less satisfied workers tend to resign while the more satisfied ones tend to remain in a job.

\section{Limitations}

Only a small sample of 100 was taken for the study. Therefore, the result cannot be generalized over a large population, as niche of study was around three colleges only. In addition, the survey instrument used in this study, UWES17 does not go into the details of asking finance related questions. This could have changed the outcome of the survey, as one of the key components of job satisfaction is the financial aspects and the benefits of it.

\section{CONCLUSIONS}

It is necessary that general working conditions in health-care industry has to be top notch to achieve excellence in any institution. Through change in workplace scenario, we can improve the working atmosphere, demographics and economic conditions. Modification in the workplace will aid in increasing the involvement of employees that will further increase productivity level in organizations and job satisfaction among workers. Thus, an organization's strategic goals must include various measures to keep its worker happy therefore leading to employees' increased commitment and dedication.

\section{REFERENCES}

[1] Turner S, Ross MK, Ibbetson RJ. Job satisfaction among dually qualified dental hygienist-therapists in UK primary care: a structural model. British Dental Journal 2011;210(4):E5.

[2] Robbins SP, Judge TA. Organizational behaviour, concepts, controversies, application. Prentice-Hall International, 1998;5:142.

[3] Locke EA. The nature and causes of job satisfaction. In: Dunnette MD, edr. Handbook of Industrial and organizational psychology. 1976;1:1297-343.

[4] Mental health and development: Targeting people with mental health conditions as a vulnerable group Geneva, World Health Organization, 2010.

[5] WHO Document Production Services, Geneva, Switzerland, 2013.

[6] Aryal N, Regmi PR, van Teijlingen E, et al. Adolescents left behind by migrant workers: a call for communitybased mental health interventions in Nepal. WHO SouthEast Asia J Public Health 2019;8(1):38-41.

[7] Leka S, Griffiths A, Cox T. Work Organization and stress: Systematic problem approaches for employers, managers and trade union representatives. (Protecting workers' health series; no. 3), WHO, 2004.

[8] Williams ES, Konrad TR, Linzer M, et al. Refining the measurements of physician job satisfaction: results from the Physician Work life Survey. SGIM Carrier Satisfaction Study Group, Society of General Internal Medicine. Med Care 1999;37(11):1140-54.

[9] Shugars DA, Hays RD, DiMatteo MR, et al. Development of an instrument to measure job satisfaction among physicians. Med Care 1991;29(8):728-44.

[10] Cameron S. Job satisfaction: the concept and its measurement, WRU Occasional Paper No. 4, Work Research Unit, Michigan. 1973.

[11] Herzberg F, Mausner B, Snyderman BB. The motivation to work. New York: John Wiley \& Sons Inc., 1959.

[12] Gardulf A, Orton ML, Eriksson LE, et al. Factors of importance for work satisfaction among nurses in a university hospital in Sweden. Scand J Caring Sci 2008;22(2):151-60.

[13] Tendolkar VD, Behere P, Sharma VK, et al. Relationship between perceived stress and mental functions and psychiatric morbidity: a survey in Maharashtra. Journal of Datta Meghe Institute of Medical Sciences University 2017;11(3):285-90.

[14] Roth SF, Heo G, Varnhagen C, et al. Job satisfaction among Canadian orthodontists. Am J Ortho Dentofacial Orthopaedics 2003;123(6):695-700.

[15] Gilmor J, Stewardson D, Shugars DA, et al. An assessment of career satisfaction among a group of general practitioners in Staffordshire. $\mathrm{Br}$ Dent J 2005;198(11):701-4.

[16] Jeong SH, Chung JK, Choi YH, et al. Factors related to job satisfaction among South Korean dentists. Community Dent Oral Epidimol 2006;34(6):460-4.

[17] Logan HL, Muller PJ, Berst MR, et al. Contributes to dentists' job satisfaction and quality of life in medical domain. J Am Coll Dent 1997;64(4):39-43. 
[18] Luzzi L, Speneer AJ, Jones K, et al. Job satisfaction of registered dental practitioners. Aust Dent J 2005;50(3):179-85.

[19] Demerouti E, Bakker AB, Nachreiner F, et al. The job demands-resources model of burnout. Journal of Applied Psychology 2001;86(3):499-512.

[20] Schaufeli WB, Salanova M, Roma VG, et al. The measurement of engagement and burnout. Journal of Happiness Studies 2002;3(1):71-92.
[21] Hudson R. Gender differences in job satisfaction: Why aren't women more dissatisfied? The Sociological Quarterly 1989;30(3):385-99.

[22] Adams A, Bond S. Hospital nurses' job satisfaction, individual and organizational characteristics. Journal of Advance Nursing 2000;32(3):536-43.

[23] Oshagbemi T. Is length of service related to the level of job satisfaction? International Journal of Social Economics 2000;27(3):213-26. 